\title{
SISTEM INFORMASI PENGADUAN PELANGGAN AIR BERBASIS WEBSITE PADA PDAM KOTA TERNATE
}

\section{INFORMATION SYSTEMS WATER CUSTOMERS COMPLAINTS WEB-BASED ON PDAM TERNATE CITY}

\author{
Nofyat $^{1}$, Adelina Ibrahim ${ }^{2}$, Arisandy Ambarita ${ }^{3}$ \\ ${ }^{1}$ Program Studi Teknik Komputer, ${ }^{3}$ Program Studi Manajemen Informatika \\ Politeknik Sains dan Teknologi Wiratama Maluku Utara \\ ${ }^{2}$ Fakultas Teknik, Program Studi Teknik Informatika \\ Universitas Muhammadiyah Maluku Utara \\ nofyat11@gmail.com
}

\begin{abstract}
Abstrak
Perusahaan Daerah Air Minum (PDAM) Kota Ternate merupakan Badan Usaha Milik Daerah (BUMD) yang pelayanan pengaduan air kepada pelanggan masih bersifat konvensional dimana pelanggan yang ingin mengadukan keluhannya harus datang ke kantor unit wilayah PDAM Kota Ternate proses penggaduanpun hanya dapat dilakukan pada hari kerja yaitu Senin - Jumat mulai dari Pukul 07.30 - 15.00 wit. Diluar waktu tersebut pelanggan tidak dapat menyampaikan keluhannya sehingga dianggap kurang efektif. Penilitian ini dilakukan pada kantor Perusahaan Air Minum (PDAM) Kota Ternate, Bertujuan untuk merancang Sistem Informasi Pengaduan Pelanggan Air Berbasis Web, Metode pengumpulan data yang digunakan Observasi, wawancara, Metode Pendekatan dan Pengembangan Sistem menggunakan pendekatan sistem Bottom-up dan model pengembangan sistem secara waterfall dengan model rancangan Sistem DFD dan ERD. Bahasa Pemrograman yang digunakan adalah HTML, CSS, PHP, serta databasenya menggunakan MySQl. Metode Pengujian Sistem yang digunakan adalah metode uji blackbox yaitu menguji setiap fungsi menu-menu yang ada pada sistem. dengan adanya sistem ini diharapkan mempermudah pelanggan dalam mengadukan keluhan air di manapun dan kapanpun tanpa harus datang ke kantor PDAM Kota Ternate
\end{abstract}

\section{Kata kunci: Sistem Informasi, Keluhan Pelanggan Air, Website}

\begin{abstract}
The regional drinking water company (PDAM) Ternate city is the Area owned enterprises (BUMD) the Ministry of water to customers complaints still are conventional where customers who wanted to denounce the complaint need to come into the Office area unit PDAM Ternate city any complaints process can only be done on a working day is Monday to Friday at clock 07.30 - 15.00 WIT, Outside those times customers cannot deliver the complaint so that it considered less effective. This research was done at the corporate office of drinking water (PDAM) Ternate city, It aims to design information systems Webbased Water Customers Complaints, Method of data collection used observation, interviews, The method of approach and system development using systems approach Bottom-up and the model of development system in waterfall model System design DFD and ERD, The
\end{abstract}


programming language used is HTML, CSS, PHP as well as its database using MySQL, Method of Testing system used is the test method black box test each function menus that are on the system, the existence of this system is expected to make it easier to sue the customer in water complaints anywhere and anytime without having to come into the Office PDAM Ternate city

\section{Keywords: Information System, Water Customer Complaints, Website}

\section{PENDAHULUAN}

Perkembangan teknologi informasi menciptakan perangkat-perangkat yang dapat membantu menyelesaikan pekerjaan dengan sangat mudah, instansi dan organisasi saat ini banyak menggunakan teknologi dalam menyelesaikan tugastugas dan pekerjaan tersebut, salah satunya dalam melakukan pelayanan-pelayanan dengan menggunakan teknologi dalam memberikan informasi kepada pelanggan yang membutuhkan dan memperoleh informasi

Menurut Kamus Besar Bahasa Indonesia (2008), pelanggan memiliki arti membeli atau menggunakan barang secara tetap. Disamping itu Pelanggan merupakan seseorang atau kelompok yang sudah memilki perjanjian dalam bisnis tertentu atau seorang yang dianggap terdaftar pada suatu layanan tertentu, pelanggan memilki kewenangan dalam melakukan sesuatu yang dianggap tidak sesuai dengan apa yang dimenjadi hak atau tujuan dari pelanggan tersebut, salah satunya yang terjadi pada pelanggan air minum di Perusahaan air minum daerah kota ternate (PDAM)

Perusahaan Daerah Air Minum (PDAM) Kota Ternate merupakan Badan Usaha Milik Daerah (BUMD) yang pelayanan informasi kepada pelanggan masih konvensional dimana pelanggan yang ingin mengadukan keluhannya harus datang ke kantor unit wilayah PDAM Kota Ternate proses penggaduan hanya dapat dilakukan pada hari kerja Senin - Jumat mulai dari Pukul 07.30 - 15.00 wit. Diluar waktu tersebut pelanggan tidak dapat menyampaikan keluhannya sehingga dianggap kurang efektif. PDAM Kota Ternate memiliki lima jenis keluhan pelanggan seperti air tidak keluar, keberatan bayar, putus sementara, ganti meter dan lain-lain.

Berdasarkan uraian sebelumnya maka perlu diusulkan suatu sistem yang berbasis web agar dapat menunjang pelayanan pengaduan pelanggan sehingga masyarakat yang ingin melakukan pengaduan dapat dilakukan pada sistem tersebut

Dengan adanya sistem informasi keluhan pelanggan yang berbasis web ini diharapkan dapat mempermudah pelanggan mengadukan keluhan air di manapun dan kapanpun tanpa harus datang ke kantor PDAM Kota Ternate

\section{Rumusan Masalah}

Berdasarkan uraian pada latar belakang masalah sebelumnya, maka dapat dirumuskan pokok permasalahan penelitian adalah: Bagaimana merancang Sistem Informasi Pengaduan pelanggan air berbasis Web pada PDAM Kota Ternate agar mempermudah pelanggan dalam melakukan proses pengaduan air pada PDAM Kota Ternate agar meningkatkan kinerja dan pelayanan petugas kepada masyarakat yang ingin melakukan pengaduan air

\section{LANDASAN TEORI}

\section{Pengertian Sistem}

Selanjutnya Menurut Yakub (2012) mendefiniskan sistem adalah sekelompok 
elemen-elemen yang terintegrasi dengan tujuan yang sama untuk mencapai tujuan. Sistem juga merupakan suatu jaringan kerja dari prosedur-prosedur yang saling berhubungan, terkumpul bersama-sama untuk melakukan suatu kegiatan atau untuk mencapai tujuan tertentu.

Menurut Bambang, Hartono (2013:10), Sistem adalah suatu himpunan dari berbagai bagian yang saling berhubungan secara terorganisasi berdasarkan fungsi-fungsinya menjadi suatu kesatuan.

\section{Pengertian Informasi}

Menurut Yakub (2012:8) pada buku Pengertian Sistem Informasi, Informasi adalah data yang diolah menjadi bentuk lebih berguna dan lebih berarti bagi yang menerimanya.

Menurut Tata Sutabri (2012:22) Informasi adalah data yang telah diklasifikasikan atau diolah atau diinterpretasikan untuk digunakan dalam proses pengambilan keputusan.

\section{Pengertian Sistem Informasi}

Menurut Sutarman (2012:13) "Sistem informasi adalah sistem yang dapat didefinisikan dengan mengumpulkan, memperoses, menyimpan, menganalisis, menyebarkan informasi untuk tujuan tertentu. Seperti sistem lainnya, sebuah sistem informasi terdiri atas input (datainstruksi) dan output (laporan, kalkulasi)".

Menurut Bambang Hartono (2013:16) "Sistem informasi adalah seperangkat komponen yang saling berhubungan, yang bekerja untuk mengumpulkan dan menyimpan data serta mengolahnya menjadi informasi untuk digunakan”.

\section{Website}

Menurut Arief (2011a:8) Pengertian Website adalah "kumpulan dari halaman web yang sudah dipublikasikan di jaringan internet dan memiliki domain/URL (Uniform Resource Locator) yang dapat diakses semua pengguna internet dengan cara mengetikan alamatnya. Hal ini dimungkinkan dengan adanya teknologi World Wide Web (WWW)

Halaman website biasanya berupa dokumen yang ditulis dalam format Hyper Text Markup Language (HTML), yang bisa diakses melalui HTTP, HTTPS adalah suatu protokol yang menyampaikan berbagai informasi dari server website untuk ditampilkan kepada para user atau pemakai melalui web browser.

\section{Pengertian Database}

Menurut Kustiyaningsih (2011:146) Database adalah struktur penyimpanan data. Untuk menambah, mengakses dan memproses data yang disimpan dalam sebuah database komputer, diperlukan system manajemen database seperti MySQL Server.

Menurut Yakub (2012:51) Basis data (database) diartikan sebagai markas atau gudang data, tempat bersarang atau berkumpul data. Prinsip utama basis data adalah pengaturan data dengan tujuan utama fleksibilitas dan kecepatan dalam pengambilan data kembali. Adapun tujuan basis data diantaranya sebagai efisisensi yang meliputi speed, space\&Accurancy, menangani data dalam jumlah besar, kebersamaan pemakaian, dan meniadakan duplikasi

\section{Pengertian Internet}

Menurut Ahmadi dan Hermawan (2013:68) Internet adalah komunikasi jaringan komunikasi global yang menghubungkan seluruh komputer di 
dunia meskipun berbeda sistem operasi dan mesin.

Menurut Sibero (2011:10) Internet adalah jaringan komputer yang menghubungkan antar jaringan secara global, internet dapat juga dapat disebut jaringan alam suatu jaringan yang luas. Seperti halnya jarigan komputer lokal maupun jaringan komputer area, internet juga menggunakan protokol komunikasi yang sama yaitu TCP/IP (Tranmission Control Protol / Internet Protocol).

\section{Pengertian PHP}

Menurut Sibero (2012:49) PHP adalah pemrograman (interpreter) adalah proses penerjemahan baris sumber menjadi kode mesin yang dimengerti komputer secara langsung pada saat baris kode dijalankan.

Menurut Kustiyahningsih (2011:114) PHP (Hypertext Preprosesor) adalah skrip bersifat bersifat server-side yang di tambahkan ke dalam HTML. PHP sendiri merupakan singkatan dari Personal Home Page Tools

\section{Pengertian Mysql}

Budi Raharjo (2011:21) MySQL merupakan software RDBMS (atau software database) yang dapat mengelola database dengan sangat cepat, dapat menampung data dalam jumlah sangat besar, dapat diakses oleh banyak user (multi-user), dan dapat melakukan suatu proses secara sinkron atau berbarengan (multi-treaded).

\section{Menurut Arief}

(2011:152)

MySQL adalah salah satu jenis database server yang sangat terkenal dan banyak digunakan untuk membangun aplikasi web yang menggunakan database sebagai sumber dan pengolahan datanya.

\section{Pelanggan}

Menurut Kamus Besar Bahasa Indonesia (2008), pelanggan memiliki arti membeli atau menggunakan barang secara tetap.

Pelanggan adalah seseorang yang menggunakan fasilitas, produk ataupun jasa secara terus menerus dari penyedia fasilitas, produk atau jasa (Solikin 2011:7). Rusman (2012: 306)

Menurut Greenberg (2010:8), pelanggan atau customer adalah individu atau kelompok yang terbiasa membeli sebuah produk atau jasa berdasarkan keputusan mereka atas pertimbangan manfaat maupun harga yang kemudian melakukan hubungan dengan perusahaan melalui telepon, surat, dan fasilitas lainnya untuk mendapatkan suatu penawaran baru dari perusahaan.

\section{Perusahaan Daerah Air Minum (PDAM)}

PDAM atau Perusahaan Daerah Air Minum merupakan salah satu unit usaha milik daerah, yang yang bergerak dalam distribusi air bersih bagi masyarakat umum. PDAM terdapat di setiap provinsi, kabupaten, dan kotamadya di seluruh Indonesia. PDAM merupakan perusahaan daerah sebagai sarana penyedia air bersih yang diawasi dan dimonitor oleh aparata parat eksekutif maupun legislatif daerah.

Perusahaan air minum yang dikelola negara secara modern sudah ada sejak zaman penjajahan Belanda pada tahun 1920an dengan nama Waterleiding sedangkan pada pendudukan Jepang perusahaan air minum dinamai Suido Syo.

\section{METODE PENELITIAN}

1. Observasi.

Observasi yaitu peneliti melakukan pengamatan secara langsung terhadap 
sistem informasi yang sementara di terapkan pada objek penelitian.

2. Wawancara.

Wawancara (interview) adalah proses memperoleh keterangan untuk tujuan penelitian dengan cara tanya jawab, sambil bertatap muka antara si penanya atau pewancara dengan si penjawab atau resonden dengan menggunakan alat yang dinamakan interview guide (padauan wawancara) (Nasir. 2011:193) dalam asnawi dan Masyhuri.

\section{Metode Pengembangan Sistem}

Metode pengembangan yang di gunakan adalah metode sekuensial linier (waterfall). Metode waterfall merupakan metode pengembangan perangkat lunak yang sistematik dan sekuensial yang mulai pada tingkat dan kemajuan sistem sampai pada analisis, desain, kode, test dan pemeliharaan.

Berikut merupakan tahapan jalur penelitian dalam metode pengembangan sistem :

1. Analisis Pada tahap ini peneliti menganalisa kebutuhan sistem. dimana mengumpulkan data dan melakukan sebuah penelitian, wawancara dan observasi.

2. Perancangan Pada tahap ini peneliti merancang sistem dengan menggunakan pendekatan terstruktur yaitu menggambar flowchart sistem yang berjalan dan sistem yang diusulkan, dan membuat diagram rincian DFD, ERD, rancangan layout.

3. Implementasi Pada tahap ini peneliti menerapkan sistem sesudah kode desain aplikasi dimasukkan dengan bahasa pemrograman html, php, css, server, xammp dan database MySQL.
4. Pengujian (test) dan pemeliharaan Pada tahap ini peneliti penguji menumenu yang ada pada sistem dengan menggunakan metode Blackbox

\section{Metode Pendekatan}

Metode pendekatan sistem yang di gunakan dalam penelitian ini adalah metode pendekatan bottom-up dimana pendekatan ini dimulai dari level bawah organisasi. Pendekatan ini dimulai dari perumusan keutuhan-kebutuhan untuk menangani transaksi dan naik ke level atas dengan merumuskan kebutuhan informasi berdasarkan transaksi tersebut

\section{Alat dan Bahan yang digunakan}

Alat dan Bahan yang digunakan dalam penelitian ini berupa perangkat keras (Hardeware) dan perangakat lunak (Software). Perangkat keras computer (Hardware) yang digunakan sebagai media untuk Perancangan Sistem Informasi pengaduan pelanggan air Berbasis Website pada kantor PDAM Kota Ternate.

1. Prosesor Intel

2. Mainboard

3. RAM 2 GB.

4. Hardisk $500 \mathrm{~GB}$

5. Printer Canon IP 2770

6. Keyboard

Sedangkan perangkat lunak yang digunakan dalam penelitian ini adalah

1. Sistem operasi windows 8. Pro 64-bit

2. Photoshop CS4

3. Sublime Text 3

4. WebServer XAMPP (Apache, MySQL)

5. Bahasa pemograman HTML, PHP, SQL, CSS, JAVASCRIP

6. Microsoft Office Visio 2007 


\section{Alur Penilitian}

Alur penelitian merupakan suatu alur tahapan yang akan dilakukan dalam penelitian agar dapat terarah, berikut merupakan tahapan alur penelitian:

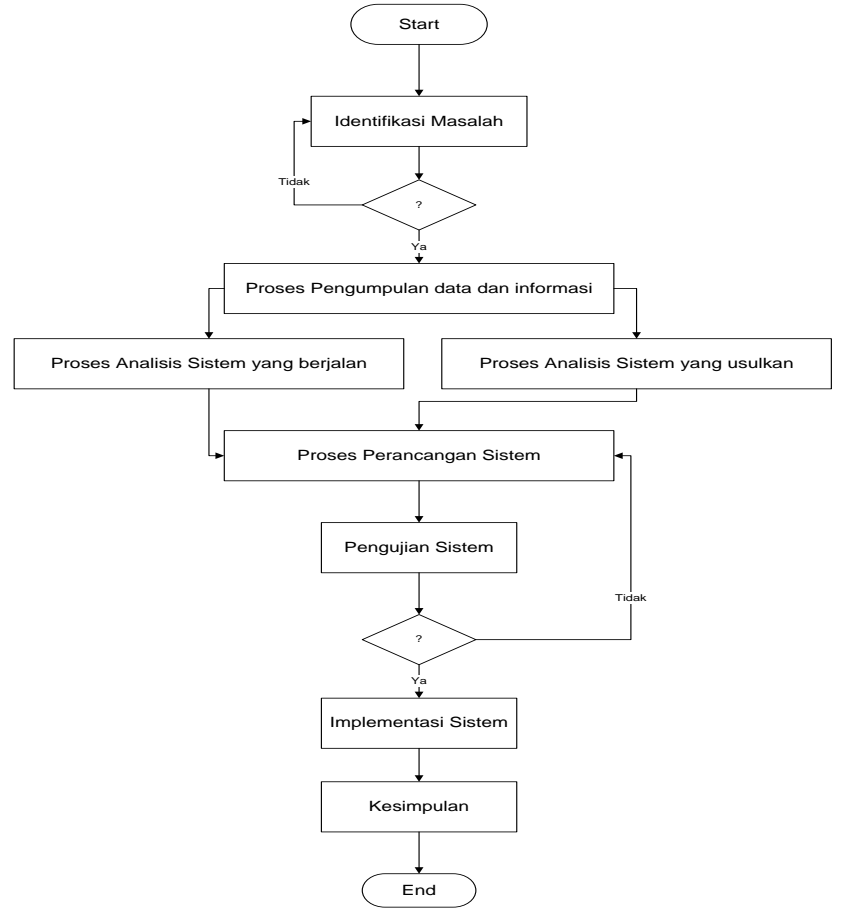

Gambar 1. Alur Penilitian

\section{Analisa Sistem yang Berjalan}

Sistem yang sedang berjalan dalam pengolahan data pada Kantor PDAM Kota Ternate masih bersifat konvensional, dimana pelanggan yang ingin melakukan pengaduan harus datang ke kantor PDAM Kota Ternate, Adapun sistem yang sedang berjalan tentang data pelangan atau keluhan, pada Kantor PDAMKota Ternate dapat dilihat pada gambar berikut

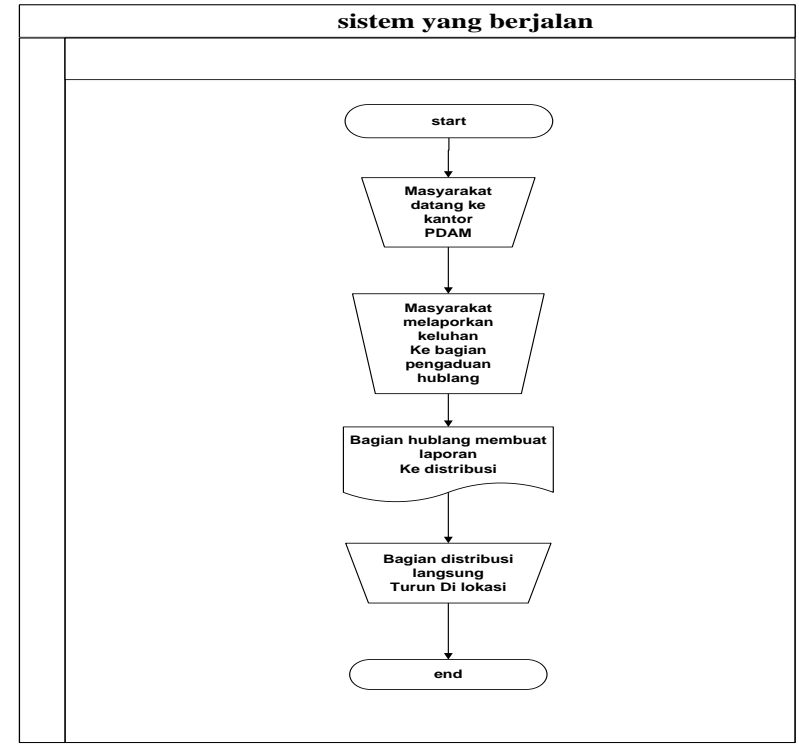

Gambar 2. Sistem yang berjalan

Hasil analisis terhadap sistem yang berjalan ditemui adanya kelemahankelemahan yang harus dicari solusinya. Adapun kelemahan-kelemahan yang ditemui, antara lain:

1. Pelangan ingin melapor keluhan harus datang ke Kantor PDAM kota ternate,

2. Petugas mengelola data pengaduan masih konvensional menggunakan Aplikasi Word dan Excel.

Berdasarkan kedua poin di atas, peneliti menyimpulkan bahwa sistem yang berjalan pada Kantor PDAM Kota Ternate belum efisien, dibutuhkan inovasi sistem yang baru sebagai penunjang kegiatan pelayanan bagi pelanggan yang ingin melakukan pengaduan

\section{Rancangan System yang Diusulkan}

Berdasarkan kelemahan-kelemahan yang terdapat pada sistem yang berjalan, maka diusulkan sistem yang berbasis web yang dapat membantu keefektifan pengaduan pelanggan air. Sistem yang diusulkan seperti pada gambar berikut 


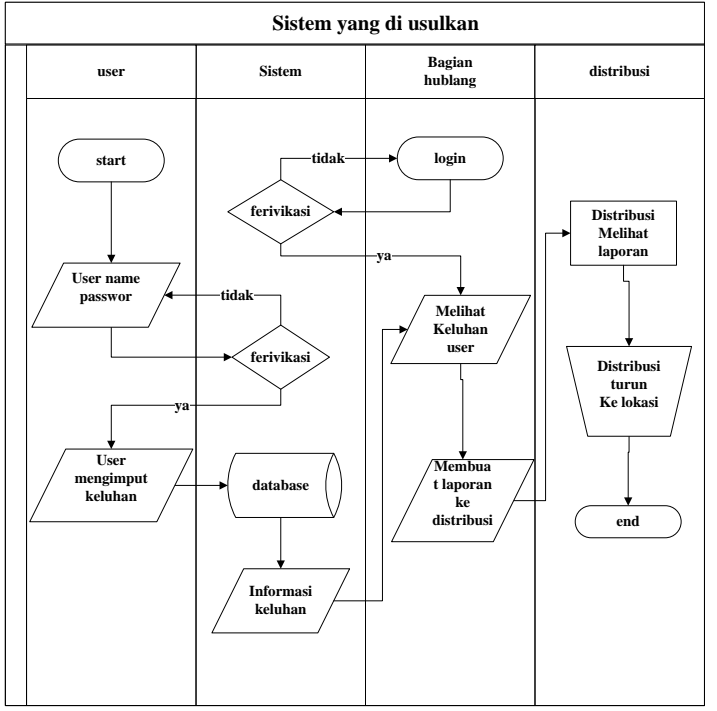

Gambar 3. Flowchart Sistem Yang

Diusulkan

Kelebihan yang terdapat pada sistem yang diusulkan, antara lain:

1. Data keluhan pelangan air tersimpan pada data base tanpa menggunakan software bantuan seperti Ms Word dan Ms Excel.

2. Petugas dapat mengelola data pelanggan yang melakukan pengaduan secara terpusat pada sistem .

3. Pelanggan yang ingin melakukan pengaduan tentang airnya tidak perlu lagi datang ke kantor PDAM kota ternate. Pelangan dapat mengakses sistem tersebut menggunakan web browser dimana saja.

\section{PERANCANGAN SISTEM}

Perancangan sistem merupakan tahapan yang dilakukan sesudah dilakukan analisis sistem dan kebutuhan sistem, dalam perancangan sistem pada penelitian ini menggunakan pendekatan model rancangan DFD diantaranya Diagram Konteks dan DFD Level 0, berikut merupakan hasil rancangan sistem diagram konteks dan DFD Level 0

\section{Diagram Konteks}

Diagram konteks merupakan model uraian rancangan sistem secara umum yang akan digunakan sebagai konsep dan cara kerja dari sistem yang diusulkan

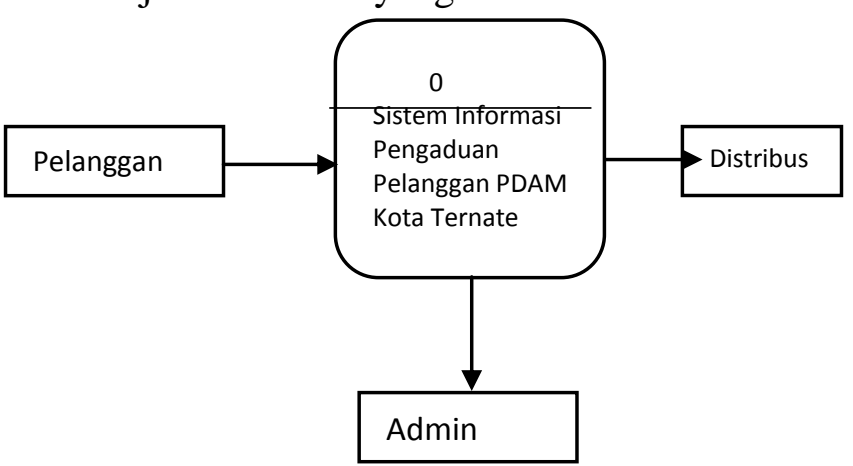

Gambar 4. Diagram Konteks

\section{Diagram Level 0}

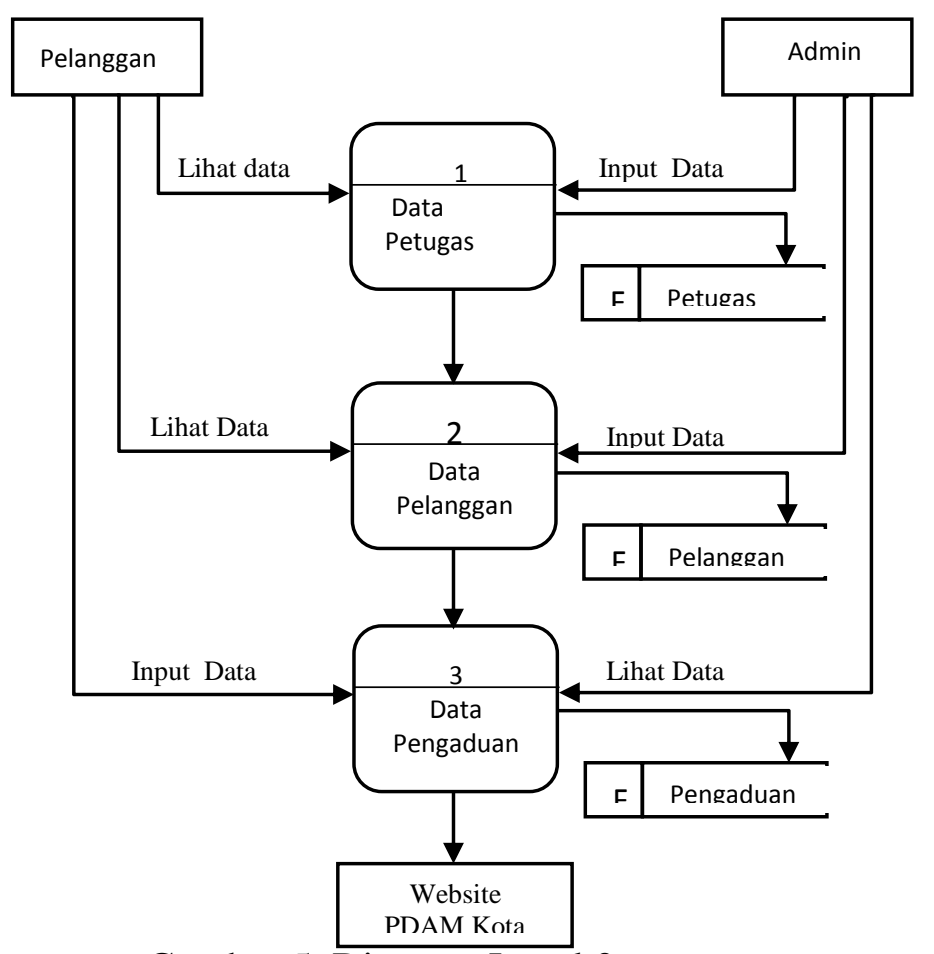

Gambar 5. Diagram Level 0

\section{ERD}

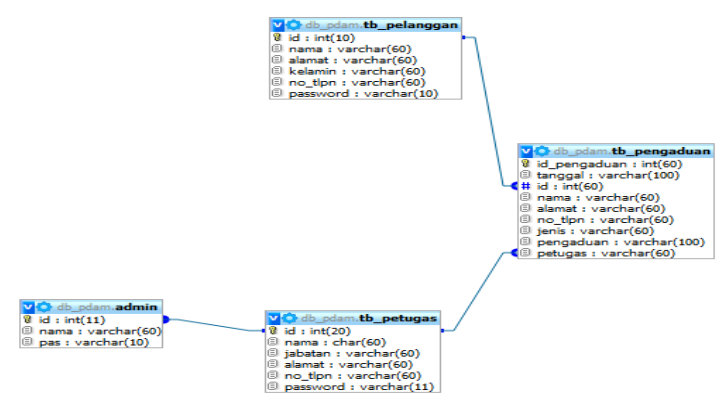

Gambar 6. ERD 
Perancangan Tabel Database

Tabel 1. Admin

\begin{tabular}{|l|c|c|c|c|}
\hline Field & Type & $\begin{array}{c}\text { Len } \\
\text { ght }\end{array}$ & $\begin{array}{c}\text { Primar } \\
\text { yKey }\end{array}$ & $\begin{array}{c}\text { AutoIncre } \\
\text { ment }\end{array}$ \\
\hline Id & integer & 11 & $*$ & $*$ \\
\hline Nama & varchar & 60 & & \\
\hline Pas & varchar & 10 & & \\
\hline
\end{tabular}

Tabel 2. data Pelanggan

\begin{tabular}{|l|c|c|c|c|}
\hline \multicolumn{1}{|c|}{ field } & Type & $\begin{array}{c}\text { Le } \\
\text { ngt } \\
\text { h }\end{array}$ & $\begin{array}{c}\text { Prim } \\
\text { aryK } \\
\text { ey }\end{array}$ & $\begin{array}{c}\text { AutoIncre } \\
\text { ment }\end{array}$ \\
\hline Id & integer & 10 & $*$ & $*$ \\
\hline Nama & varchar & 60 & & \\
\hline Alamat & varchar & 60 & & \\
\hline Kelamin & varchar & 60 & & \\
\hline no_tlpn & integer & 60 & & \\
\hline password & varchar & 10 & & \\
\hline
\end{tabular}

Tabel 3. Pengaduan

\begin{tabular}{|l|c|c|c|c|}
\hline \multicolumn{1}{|c|}{ field } & Type & $\begin{array}{c}\text { Le } \\
\text { ngt } \\
\mathbf{h}\end{array}$ & $\begin{array}{c}\text { Pri } \\
\text { mar } \\
\text { yKe } \\
\mathbf{y}\end{array}$ & $\begin{array}{c}\text { AutoInc } \\
\text { rement }\end{array}$ \\
\hline Id_pengaduan & integer & 60 & $*$ & $*$ \\
\hline Tanggal & date & & & \\
\hline Id & integer & 60 & & \\
\hline Nama & varchar & 60 & & \\
\hline Alamat & text & 60 & & \\
\hline no_tlpn & integer & 60 & & \\
\hline Jenis & varchar & 60 & & \\
\hline pengaduan & varchar & 100 & & \\
\hline Petugas & varchar & 60 & & \\
\hline
\end{tabular}

Tabel 4. Data_Petugas

\begin{tabular}{|l|c|c|c|c|}
\hline \multicolumn{1}{|c|}{ field } & Type & $\begin{array}{c}\text { Le } \\
\text { ng } \\
\text { th }\end{array}$ & $\begin{array}{c}\text { Prima } \\
\text { ryKey }\end{array}$ & $\begin{array}{c}\text { AutoIncre } \\
\text { ment }\end{array}$ \\
\hline Id & integer & 10 & $*$ & $*$ \\
\hline Nama & varchar & 60 & & \\
\hline Jabatan & varchar & 60 & & \\
\hline Alamat & varchar & 60 & & \\
\hline no_tlpn & integer & 60 & & \\
\hline password & varchar & 11 & & \\
\hline
\end{tabular}

\section{IMPLEMENTASI SISTEM}

Implementasi sistem merupakan tahapan yang dilakukan setelah perancangan dan pengkodean sistem yang sudah dibuat akan diletakkan dan dilakukan uji sistem
Login pelanggan

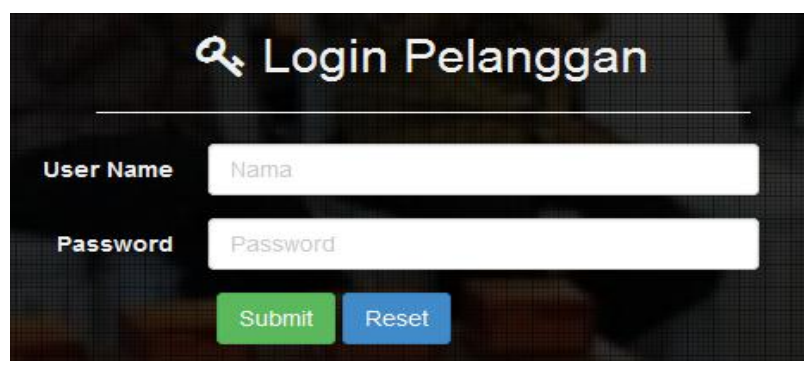

Gambar 7. Menu login Pelanggan

\section{Halaman Menu Home}

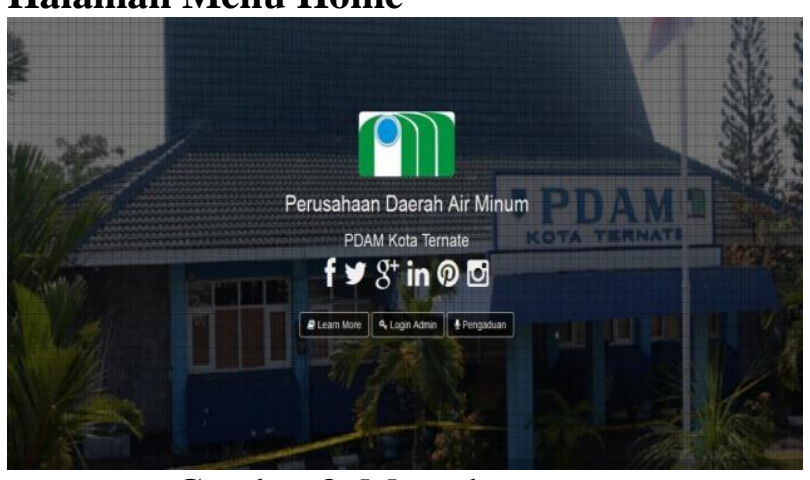

Gambar 8. Menu home

\section{Halaman Data Pelanggan}

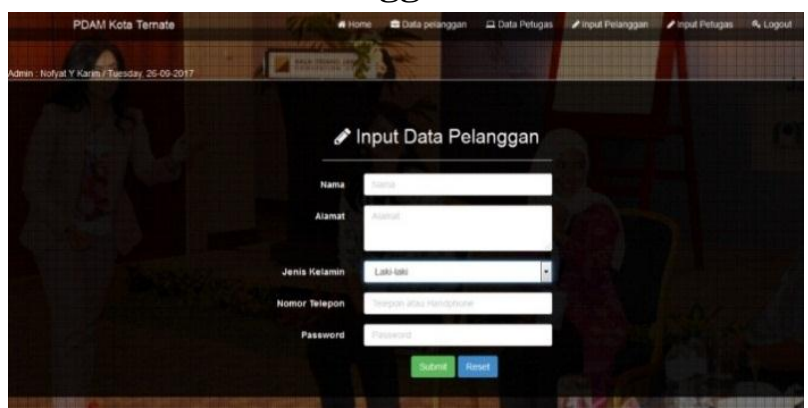

Gambar 9. Menu Data pelanggan

\section{Menu Admin}

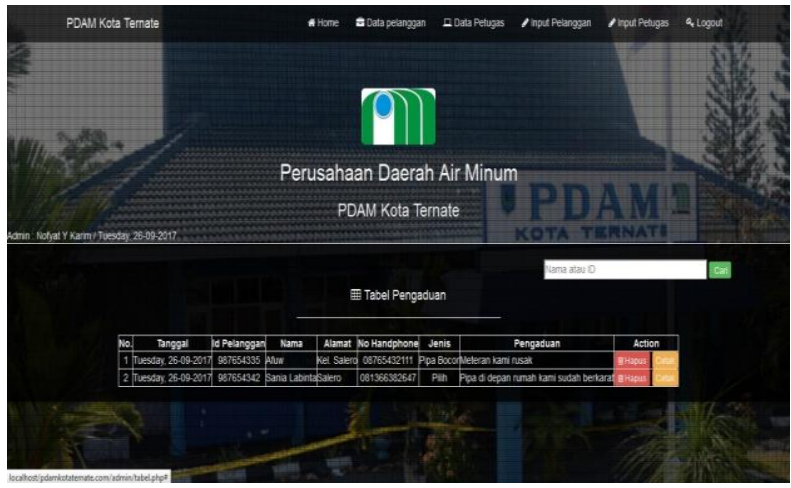

Gambar 10. Menu Admin 
Menu Admin Kelola Data Pelanggan

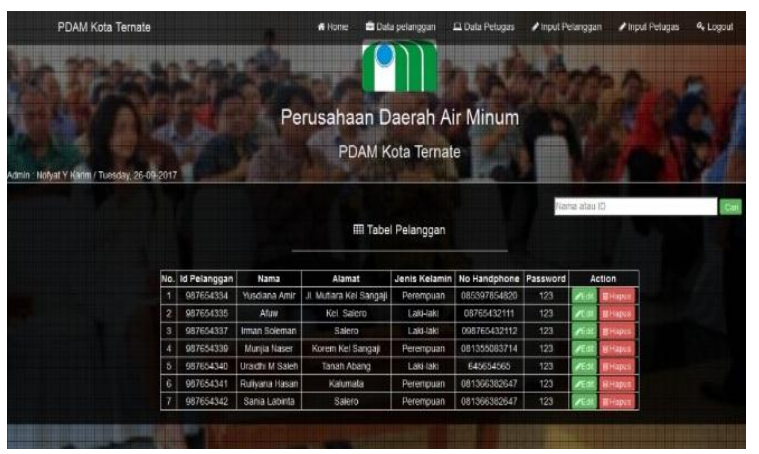

Gambar 11. Menu Admin Kelola Data

Pelanggan

\section{Menu Admin Kelola Data Pengaduan}

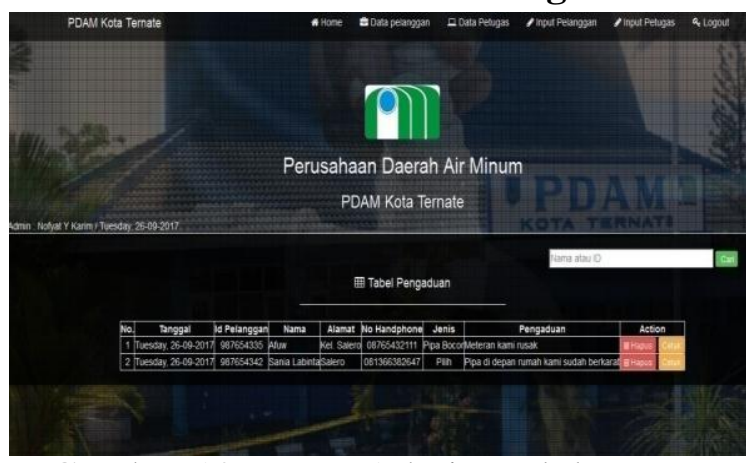

Gambar 12. Menu Admin Kelola Data

Pengaduan

\section{Pengujian Sistem}

Tabel 5. Pengujian Blackbox

\begin{tabular}{|c|c|c|c|}
\hline $\begin{array}{c}\text { Item } \\
\text { Pengujia } \\
\text { n }\end{array}$ & $\begin{array}{c}\text { Deskrips } \\
\text { i }\end{array}$ & File yang diuji & $\begin{array}{c}\text { Hasil } \\
\text { Test }\end{array}$ \\
\hline Login & $\begin{array}{l}\text { Melakuka } \\
\mathrm{n} \text { login ke } \\
\text { admin } \\
\text { dan } \\
\text { pelangga } \\
\mathrm{n}\end{array}$ & $\begin{array}{l}\text { loginAdmin.php } \\
\text { loginPelanggan.p } \\
\text { hp }\end{array}$ & $\begin{array}{c}\text { Sukse } \\
\text { s }\end{array}$ \\
\hline $\begin{array}{l}\text { Informas } \\
\text { i }\end{array}$ & $\begin{array}{l}\text { Melihat } \\
\text { informasi } \\
\text { PDAM } \\
\text { Kota } \\
\text { Ternate }\end{array}$ & Index.php & $\begin{array}{c}\text { Sukse } \\
\text { s }\end{array}$ \\
\hline $\begin{array}{l}\text { Input } \\
\text { Pengadu } \\
\text { an }\end{array}$ & $\begin{array}{l}\text { Pada saat } \\
\text { pelangga } \\
\mathrm{n} \\
\text { mengadu } \\
\mathrm{di} \text { form } \\
\text { pengadua } \\
\mathrm{n}\end{array}$ & $\begin{array}{c}\text { pelanggan/home. } \\
\text { php }\end{array}$ & $\begin{array}{c}\text { Sukse } \\
\text { s }\end{array}$ \\
\hline $\begin{array}{l}\text { Admin } \\
\text { melihat } \\
\text { pengadu } \\
\text { an }\end{array}$ & $\begin{array}{l}\text { Saat } \\
\text { admin } \\
\text { login } \\
\text { akan }\end{array}$ & Table.php & $\begin{array}{c}\text { Sukse } \\
\text { s }\end{array}$ \\
\hline
\end{tabular}

\begin{tabular}{|c|c|c|c|}
\hline $\begin{array}{l}\text { pelangga } \\
\mathrm{n}\end{array}$ & $\begin{array}{l}\text { dihadapk } \\
\text { an } \\
\text { dengan } \\
\text { table } \\
\text { pengadua } \\
\mathrm{n}\end{array}$ & & \\
\hline $\begin{array}{l}\text { Admin } \\
\text { melihat } \\
\text { data } \\
\text { pelangga } \\
\mathrm{n}\end{array}$ & $\begin{array}{l}\text { Admin } \\
\text { mengelol } \\
\text { ah data } \\
\text { pelangga } \\
\text { n berupa } \\
\text { edit dan } \\
\text { hapus }\end{array}$ & $\begin{array}{c}\text { Table- } \\
\text { pelanggan.php }\end{array}$ & $\begin{array}{c}\text { Sukse } \\
\text { s }\end{array}$ \\
\hline $\begin{array}{l}\text { Admin } \\
\text { melihat } \\
\text { data } \\
\text { petugas }\end{array}$ & $\begin{array}{l}\text { Admin } \\
\text { mengelol } \\
\text { ah data } \\
\text { petugas } \\
\text { berupa } \\
\text { edit dan } \\
\text { hapus }\end{array}$ & Tb_petugas.php & $\begin{array}{c}\text { Sukse } \\
\text { s }\end{array}$ \\
\hline $\begin{array}{l}\text { Input } \\
\text { pelangga } \\
\text { n }\end{array}$ & $\begin{array}{l}\text { Admin } \\
\text { menginpu } \\
\mathrm{t} \\
\text { pelangga } \\
\mathrm{n} \text { baru. }\end{array}$ & $\begin{array}{c}\text { Input_pelanggan. } \\
\text { php }\end{array}$ & $\begin{array}{c}\text { Sukse } \\
\text { s }\end{array}$ \\
\hline $\begin{array}{l}\text { Input } \\
\text { petugas }\end{array}$ & $\begin{array}{l}\text { Admin } \\
\text { menginpu } \\
\text { t petugas } \\
\text { baru }\end{array}$ & $\begin{array}{c}\text { Input_petugas.ph } \\
\text { p }\end{array}$ & $\begin{array}{c}\text { Suske } \\
\text { s }\end{array}$ \\
\hline $\begin{array}{l}\text { Edit } \\
\text { pelangga } \\
\text { n }\end{array}$ & $\begin{array}{l}\text { Admin } \\
\text { dapat } \\
\text { mengedit } \\
\text { dan men- } \\
\text { update } \\
\text { data } \\
\text { pelangga } \\
\text { n tanpa } \\
\text { menggant } \\
\text { i id } \\
\text { pelangga } \\
\mathrm{n}\end{array}$ & $\begin{array}{c}\text { Edit_pelanggan.p } \\
\text { hp }\end{array}$ & $\begin{array}{c}\text { Sukse } \\
\text { s }\end{array}$ \\
\hline $\begin{array}{l}\text { Edit } \\
\text { Petugas }\end{array}$ & $\begin{array}{l}\text { Admin } \\
\text { dapat } \\
\text { mengedit } \\
\text { dan men- } \\
\text { update } \\
\text { data } \\
\text { petugas } \\
\text { tanpa } \\
\text { menggant } \\
\text { i id } \\
\text { petugas. }\end{array}$ & Edit_petugas.php & $\begin{array}{c}\text { Sukse } \\
\text { s }\end{array}$ \\
\hline
\end{tabular}

\section{KESIMPULAN}

Berdasarkan hasil implementasi dan pengujian sistem maka dapat disimpulkan, diantarannya adalah: 1) sistem ini dapat mempermudah pelanggan dalam 
melakukan pengaduan di sistem tanpa harus datang ke kantor PDAM Kota ternate kapan saja pada sistem. 2). Meningkatkan kinerja dan pelayanan petugas informasi dalam memberikan informasi pengaduan pelangga air

Berdasarkan kesimpulan tersebut maka diajukan saran sebagai berikut: 1). Agar pelanggan dapat melakukan registrasi di sistem secara otomatis yang terkoneksi dengan id pelanggan yang sudah terdaftar sebagai pelanggan sebelumnya. 2). diharapkan lebih banyak fasilitas menu yang dapat ditampilkan agar dalam penyajian informasi lebih menarik.

\section{DAFTAR PUSTAKA}

Departemen Pendidikan Indonesia (2008). Kamus Besar Bahasa Indonesia. Jakarta: Balai Pustaka

Greenberg, P. 2010. Customer Relationship Management as the Speed of Light: Fourth Edition McGraw-Hill.

Arief M Rudianto. 2011. Pemrograman Web Dinamis menggunakan PHP dan MYSQL. C.V ANDI OFFSET. Yogyakarta.

Alexander F. K. Sibero. 2011. Kitab Suci Web Programming. Yogyakarta: Mediakom

Budi Raharjo. 2011. Belajar Otodidak Membuat Database Mengunakan MySQL. Informatika. Bandung.

Kustiyaningsih, Yeni (2011). Pemrograman Basis Data Berbasis Web Yogyakarta Graha Ilmu.

Moekijat. Prasojo. Pengantar Sistem Informasi Manajemen Bandung: $C V$. Remadja Karya. 2011.

Saputra, Agus. 2011. Pemrograman CSS Untuk Pemula. Jakarta: PT. Gramedia.
Solihin, 2011. Pengantar Analisis Kebijakan Publik. UPT Penerbitan Universitas Muhammadiyah, Malang

Tata Sutabri. 2012. Analisis Sistem Informasi. Andi. Yogyakarta

Yakub. (2012). Pengantar Sistem informasi: Grahallmu.Yogyakarta

Rusman. 2012. Belajar dan Pembelajaran Berbasis Komputer. Bandung: Alfabeta.

Sutarman. 2012. Buku Pengantar Teknologi Informasi. Jakarta: Bumi Aksara

Agung. Gregorius. 2012. Buku Pintar HTML + CSS3 + Dreamweaver. Yogyakarta: $\quad$ Elex Media Komputindo

Hartono, Bambang. 2013. Sistem Informasi Manajemen Berbasis Komputer. Jakarta: Rineka Cipta.

Widya ari bintarawan 2013, Pengembangan Sistem Pengaduan Pelanggan Pada Perusahaan Air Minum Kota Salatiga, Skrpsi Universitas Kristen Satya Wacana Institutional Repository 2013, Kota SalaTiga

Muhammad Beni Saputra 2015, Sistem Informasi Keluhan Pelanggan Berbasis Web Pada pdam Tirta Musi Palembang, skripsi Universitas Bina Darma, palembang

Wikipedia Bahasa Indonesia, Ensiklopedia bebas, PDAM

https://id.wikipedia.org/wiki/PDAM

Sucianti Saiful, Arisandy Ambarita, Pembuatan Aplikasi Web Pencarian Jasa Pembantu Rumah Tangga (PRT) Di Kota Ternate, IJISIndonesian Journal On Information System, Volume 2 Nomor 2 September 2017, ISSN 2548-6438 